\title{
AN ANATOMICAL AND EXPERIMENTAL STUDY OF TEMPORAL AND OCCIPITAL ASSOCIATION AREAS
}

\author{
LLOYD J. LEMMEN \\ Laboratory of Comparative Neurology, Department of Anatomy, \\ University of Michigan, and Department of Surgery, \\ Section of Neurosurgery, University Hospital, Ann Arbor ${ }^{2}$ \\ TWENTY FIGURES
}

This paper is concerned with a study of the cortical association regions bordering on and related to the visual and auditory projection areas of the brain of Macaca mulatta. An attempt has been made to correlate the findings from anatomical and experimental work with the data on these association areas available in the literature. The studies on behavior presented in this report serve only as an introduction to understanding of the infinitely complex functions of the visual and auditory association areas of the macaque.

This paper is a part of the series of studies on the cerebral cortex and the midbrain of this primate being carried on in the Department of Anatomy at the University of Michigan. The author wishes to thank the sponsors of the Brower and Arn and the Clover research funds of the University of Michigan Medical School for the generous grants which made possible this work. He is indebted to Professor Elizabeth $\mathrm{C}$. Crosby under whose careful direction this paper was planned and executed.

\section{MATERIALS AND METHODS}

Altogether 7 specimens of Macaca mulatta were operated upon and their brains compared with a series through the nor-

${ }^{1}$ A dissertation submitted in partial fulfilment of the requirements for the degree of Doctor of Philosophy in the University of Michigan, 1951. 
mal brain of the macaque from the Huber Comparative Neurological Collection which were stained by the Weil technique. The experimental material was prepared by the Marchi technique using the Swank and Davenport modification ('35). The technical difficulties and apparent differences in optimal staining times for various fiber systems, of necessity, limit the conclusions which can be drawn from a study of this nature. The cortical stimulation was carried out under variable depths of ether anesthesia using a minimal faradic current. The results of electrical stimulation are modified by many factors, such as: temperature, blood supply, shock, flow of cerebrospinal fluid, type and depth of anesthesia, and type and intensity of stimulating current (Hines, '44). Inasmuch as the numerical description of the macaque brain is current in most of the present day literature, an attempt will be made to approximate and correlate these findings in terms of the numerical nomenclature used in the brain map of Macaca mulatta by MeCulloch ('44) in connection with neuronography (based on Brodmann's classification) and the cytoarchitectural map of the Macaca mulatta described by Bonin and Bailey ('47). In most cases a trephine opening was made through the skull and the opening enlarged as necessary for more adequate exposure. Occasionally a bone flap was turned for added protection from brain herniation through the dural defects. The elevated temporal muscle provided an additional protective layer in the temporo-occipital area. In all instances, unless otherwise indicated, the surgical lesion was made with an electrical cautery on the exposed cortex. When stimulating the basal surface of the occipital lobe, an attempt was made to insulate the region with a thin sheet of rubber to eliminate the possibility of a spread of the current to the surrounding dura and muscle.

Preoperative and postoperative testing of the animals was done as time permitted. In the preliminary experiments, a visual box discrimination test (visual box test) was employed. The two gray boxes used in this test (and by Poirier, '51) were entirely similar except that the front of one was square 
and the other had a semioval portion (fig. 1) taken off the top part of the front of the box. In addition, an auditory box test was used in the earlier experiments. These two white boxes had similar external appearances; one contained a hidden bell and the other some hidden weights in order to balance the weight of the boxes (fig. 1). In these tests, the boxes had strings attached to them which led to the test cage. The object in this test was to have the monkey pull in the box containing the food. In the visual discrimination test, the animal was taught to pull toward the eage only the box with the semioval defect. This box in each case was baited with food. In the bell discrimination test, the boxes were elevated above the floor on a board and, when the animal pulled the box toward him, the box fell to the floor and the bell rang. In this test, the animals were taught to react positively to sound. The technique of pulling in a selected box had been described by Klüver ('33).

It was soon apparent that the tests were too crude for fine auditory discrimination. In the later phases of the work, the animals were studied in a specially built cage. Figure 2 illustrates the interior of the cage toward the side that contained the doors. Behind the partly opened door was a second set of doors; behind each of the first doors was a microswitch with which contact was made as the door was opened. Thus, connections were established with a bell or buzzer built on the back of the cage (fig. 3) or with the small lights illustrated between the doors in figure 2 . Figure 3 shows the master switch panel, which was controlled by the examiner. In the case reported in which this apparatus was used, the animal was tanght to distinguish between the sound made by the buzzer versus no sound. He was taught to react positively to the sound. The monkey remained in the cage during the entire testing period. The tests were carried out using bread, apples, bananas, or raisins as bait. These were dropped into the opening behind the second door after the completion of the test. The closing of the doors by the examiner initiated a new trial period. The correct response was the one which 
resulted when the animal opened only the door which initiated the ringing of the buzzer. An error was committed if the animal opened the door which set off no sound. After the initial fright period, the monkey adjusted to the presence of the examiner and gradually learned the test. Of two other animals not reported in the experimental data, one learned the test after 1000 trials and another (with a small lesion in the superior temporal gyrus) failed to learn the test after 1300 trials.

\section{EXPERIMENTS}

Monkey no. 1

This was a healthy young female monkey on which a left temporal craniotomy was performed on June 22, 1949. Cortical stimulation was carried out on area 19 (A and B, fig. 4) and a cortical lesion was made in this area. No movements were noted on stimulation in this area at varying depths of anesthesia. Following an uneventful recovery, a right temporal craniotomy was done on June 30, 1949. On area 19 (C, fig. 4) about $1 \mathrm{~cm}$ below the inferior occipital sulcus, faradic stimulation resulted in a facial grimace characterized by an elevation of the right lip and a blinking of the right eyelid. Stimulation of the superior temporal lobe (F, fig. 4) resulted in conjugate horizontal deviation of the eyes toward the opposite side. A cortical lesion was made in area 19 (B and C, fig. 4). Convalescence was uneventful and the animal was sacrificed, at the end of 14 days, for Marchi study.

Postmortem examination revealed a lesion both in the left occipital lobe in area 19 ( $\mathrm{A}$ and $\mathrm{B}$, fig. 5) and in the right occipital lobe in area $19(\mathrm{C}$ and $\mathrm{D}$, fig. 6$)$. The Marchi material corroborated the extent of these lesions. From area 19 (C, fig. 4) fibers passed across the white matter of the hemisphere with the visual radiations and accompanied them into the internal capsule. Some fibers swung dorsalward and passed into the corpus callosum; others continued forward with the visual radiations; these fibers (cortico-striate tract) swung lateralward to reach the most caudal and ventral aspects of the 
putamen where the degenerated fibers ended. Some degenerated fascicles (cortico-rubral tract) passed more medially along with the visual radiations, swinging medially over the dorsal surface of the lateral geniculate nucleus, rostral to the visual radiations, where they passed medialward into the tegmentum of the midbrain ending in the large-celled part of the red nucleus and the nucleus mesencephalicus profundus. In the region of the nigro-cortical fibers, fine degenerations could be traced to the caudal end of the substantia nigra (pars lateralis), but no definite connection between the fibers from area 19 and this degeneration could be demonstrated.

From the superficial lesion of area 19 (A and B, fig. 4) on the right, fibers (internal cortico-tectal tract, preoccipital division) passed forward into the internal capsule, where they coursed dorsomedialward across the pulvinar into the superior colliculus, intersecting non-degenerated fibers from the dorsal part of the pulvinar. At this point the fibers were lost.

Monkey no. 2

On July 23, 1949, a left temporal craniotomy was performed on this young female animal. Electrical stimulation of the posterior part of the superior temporal gyrus (F, fig. 4) and area 19 (A and $\mathrm{B}$, fig. 4) gave no movement. About $1 \mathrm{~cm}$ below the right inferior occipital sulcus stimulation of area 19 (C, fig. 4) resulted in grimaces on the left side of the face and eyelid movements. Slightly below this (D), tensing of the neck muscles was noted with an extension movement, and farther downward and medialward on the basal surface of the occipital lobe $(\mathrm{E})$, tensing of the chest muscles and respiratory irregularity were observed. A cortical lesion was made in areas 22 and 19 (fig. 7). Following an uneventful recovery, a right temporal craniotomy was done on July 29 , 1949. Stimulation of area 19, at C, resulted in left facial grimaces characterized by elevation of the lips and blinking of the eyelids, at D, tensing of the neck muscles, and at $\mathrm{E}$, tensing of the chest muscles and respiratory irregularities. 
The third operation on August 3, 1949, was a bilateral reopening of the two previous craniotomy wounds. Stimulation of right area 19 (A), where a cortical lesion had been made previously, resulted in neck movements toward the opposite side. Above $A$, in intact cortex, stimulation resulted in a conjugate deviation of the eyes toward the left in a downward direction. On the left side in the cortical lesion made on July 29, 1949, in area 19 (A and B, fig. 7), stimulation at A resulted in neck movements toward the right, and at $B$, elevation of the lip on the side of stimulation. The cortical lesion was enlarged as indicated in figure 8. Following a reopening craniotomy on August 9, 1949, in which no stimulation was carried out, the animal succumbed to a meningeal infection. Because of the meningeal infection and the larger lesion made in the more anterior portions of the temporal lobe during the last operative procedure two days before death, no microscopic study was carried out, except for sections confirming the meningeal infection.

In preoperative testing from June 25, 1949, to July 9, 1949, this animal had been able to learn the visual discrimination test (visual box test). From July 9, 1949, to July 20, 1949, the animal was able to learn the auditory discrimination test (bell box test). Following the left cortical procedure on July 23,1949 , the animal retained perfectly the memory of these auditory and visual discrimination tests. After the right operative procedure on July 29, 1949, the animal showed no loss of memory for the auditory discrimination test. Following the bilateral operative procedure on August 3, 1949, the animal showed no errors in the visual and auditory tests. After the last operative procedure on August 29, 1949, the animal was too ill to be tested.

\section{Monkey no. 3}

On July 25, 1949, a left fronto-temporal craniotomy was done on this young female monkey with exposure of Brodmann's areas 4, 6, and 8. Electrical stimulation at $Z$ (fig. 4) 
resulted in a tensing of the neck muscles, at $\mathrm{Y}$ in movements of the right arm, at $\mathrm{X}$ in right facial grimaces, at $\mathrm{W}$ in left facial movements and eyelid blinking, at $\mathrm{V}$ in conjugate eye movements to the right, at $U$ in conjugate eye movements downward and to the right. A superficial cortical lesion was made surgically in the areas of $\mathrm{U}, \mathrm{V}, \mathrm{W}, \mathrm{X}$, and part of $\mathrm{Y}$ and $Z$ (fig. 9). The temporo-occipital area was then exposed over area 19 (fig. 4) where stimulation at $\mathrm{C}$ resulted in lip and eyelid movements on the right side, at $\mathrm{D}$, in extension movements of the neck muscles, and at $\mathrm{E}$, in tightening and tensing of chest muscles. A cortical lesion was also made at C. Immediately postoperatively, and for about one hour after she had recovered from the anesthesia, the monkey tended to walk in a circle toward the side of the lesion. There was no inequality of the pupils and the animal had no difficulty in opening and closing the eyelids. This phenomenon has been referred to as forced circling (Smith, '44; and others). Postoperatively this animal had weakness of the right upper extremity, tending to use the left hand in taking and eating food.

On August 1, 1949, a right fronto-temporal eraniotomy was carried out with exposure of Brodmann's areas 4, 6, and 8 (fig. 4). Electrical stimulation at $\mathrm{Y}$ resulted in tensing of the arm muscles, at $\mathrm{X}$ and $\mathrm{W}$ in face and eyelid movements, at $\mathrm{V}$ in conjugate deviation of the eyes to the left, at $U$ in conjugate deviation of the eyes downward and to the left. A cortical lesion was made at $\mathrm{U}, \mathrm{V}, \mathrm{X}, \mathrm{W}$. The occipital lobe was then exposed over area 19 , and stimulation at $C$ resulted in lip and eyelid movements on the right side, and, at $\mathrm{D}$, in tensing of the neck muscles. A cortical lesion was then made at C (fig. 10).

Postoperatively no voluntary movements of the facial muscles were apparent. W. K. Smith ('44) has also called attention to the expressionless facies after bilateral ablation of the frontal eye fields. This animal, when eating, would raise the food only about one inch from the ground and then bring his head down to the food. His mouth was frequently found to 
be stuffed with food and there was partly eaten food scattered over his body. Because of this animal's poor hygiene and his manipulation of the operative wound, an abscess developed in the left operative area and this was subsequently drained. At the end of the two weeks' period there was some improvement in the animal's habits. Grossly, at postmortem, there was considerable herniation of the brain in the frontal region especially on the left $s^{\circ}$ de. The Marchi sections in this case were of limited value for fiber tract study.

\section{Monkey no. 4}

On September 20, 1949, a left temporal craniotomy was performed on this young female monkey, and stimulation carried out in area 19 (fig. 4). At $\mathrm{C}$, there was elevation of the left lip and, at D, a turning of the chin downward to the left across the midline with associated turning of the neck and movements of the shoulder muscles. In this same area, a tensing of the forearm muscles was noted with extension movements. Upon turning a flap in this area, a larger than usual vessel, coursing through the inferior occipital sulcus, was opened and required coagulation for hemostasis. A superficial cortical lesion was made in the anterior portions of $\mathrm{C}$ and $\mathrm{D}$. On the 4th postoperative day, the monkey began having focal convulsive movements, initiated by smacking of the lips for 30-45 seconds, followed by twitching movements of the face on the left, which progressed to the right side of the face, and were then followed by a spread to the neck muscles and right arm. The forearm had alternating rapid extension and flexion movements with the hand clinched in a fist; the neck was drawn backward and toward the left. The duration of the seizure was two to two and one-half minutes, following which the monkey appeared clear for 10-15 minutes, running about, eating, and drinking. The following day the seizure had become almost a continuous grand mal convulsion; the animal was semi-comatose and appeared terminal. The convulsive movements were par- 
tially controlled under the ether anesthesia used during the re-exploration of the wound. The wound was found to be clean with no gross evidence of infection or hemorrhage. A large portion of the brain anterior to the operative lesion was removed blindly through the previous bone defect. The convulsive movements cleared in 24 hours and the remaining. postoperative course was uneventful until the animal was sacrificed on the 14th postoperative day.

At postmortem, the lesion was found to involve the anterior portion of $\mathrm{C}$ and $\mathrm{D}$. It extended anteriorly into the temporal lobe as shown in figure 11. The Marchi material indicated that the injury in this case was considerably larger than that which could be attributed to the surgical lesion, due, perhaps, to an anemic infaret resulting from the coagulation of the blood vessels lying in the inferior occipital sulcus. The lesion continued mediad involving, in part, the superior temporal gyrus and the middle and inferior temporal gyri, and could be followed deeply into the lateral aspects of the claustrum. The exact origin of the fibers in this case was difficult to determine. A considerably greater number of degenerated fibers passed into the temporo-occipito-parieto-pontine bundle than when the lesion involved only the superior temporal gyrus. More caudally, cortico-geniculate and cortico-tectal fascicles were found in company with bundles passing to auditory cortex. Degenerated fibers passed from the caudal aspect of the lesion toward the caudal end of the putamen. Some of these could be traced medially across the internal capsule where they reached the lateral aspect of the substantia nigra, which they followed to its caudal limits. Degeneration granules accumulated laterally to the caudal end of the lateral geniculate nucleus. These could be traced across the pulvinar entering the most caudal attachment of the pulvinar to the superior colliculus (external cortico-tectal tract) where they swung dorsally to enter the stratum zonale of the superior colliculus (fig. 15).

In the right thalamus a lesion (fig. 16), probably vascular in origin, had produced a degeneration in the dorsolateral 
portion of the ventral nucleus of the thalamus, beginning caudal to the level of the mammillary bodies, extending dorsalward into the internal capsule, and forward and laterad into the white matter of the parietal operculum of the island. Caudally this lesion extended into the medial aspects of the pulvinar, slightly rostral to where the superior colliculus separated from the hemisphere. From this lesion, degenerated fibers passed downward through the external capsule to end on the temporal operculum of the island. A large number of degenerated fibers passed dorsad in the sensory radiations to the parietal lobe. From the lesion in the thalamus, degenerated fibers (thalamo-cortical tract) could be followed, either sublenticularly or through the putamen, to the superior temporal gyrus, but their exact termination could not be ascertained. Ventrally the lesion in one area involved bundles related to auditory association cortex. Degenerated fibers (probably cortico-tectal tract, auditory division) passed caudad along the medial aspect of the medial geniculate nucleus to the inferior colliculus. Degenerated fibers (probably parieto-rubral tract) extended mediad, slightly anterior to the level of the auditory radiations, to pass into the caudal portion of the red nucleus. Other degeneration granules (parieto-pontine tract) swung downward more rostrally, into the lateral portion of the cerebral peduncle. At more caudal levels, degenerated fibers were seen in the pars lateralis of the substantia nigra. From the lesion on the parietal operculum, fibers proceeded through the capsula extrema and the capsula externa to the island and to the opercular surface of the temporal lobe.

\section{Monkey no. 5}

On September 27, 1949, a left temporal craniotomy was performed over the superior temporal gyrus of this young female monkey. Stimulation (F, fig. 4) resulted in no definite eye movements, and no surgical lesion was made. On October 4,1949 , a right temporal craniotomy was performed and 
stimulation at a point corresponding to $\mathrm{F}$ of the left hemisphere evoked conjugate eye movements to the opposite side. A surgical lesion was made at F (fig. 4). More anteriorly, on the superior temporal gyrus, eyelid and face movements were noted on stimulation. The minimal faradic current used to obtain movements in area 4 was sufficient to produce those movements described at $\mathrm{F}$ on the right superior temporal gyrus. The postoperative course was uneventful and the animal was sacrificed 14 days postoperatively.

Gross examination of the brain at postmortem showed a small surgical lesion in the right superior temporal gyrus (fig. 12). Marchi stain revealed a small lesion extending into the white matter of the left superior temporal gyrus with a more superficial involvment in the parietal cortex at the rostral level of the surgical lesion.

At the level of the lesion the degenerated fibers swung across the white matter of the superior temporal gyrus. where some of them turned into the temporal operculum of the island. Fine degenerated fibers could be seen to turn dorsalward at the level of the capsula externa and capsula extrema where they appeared to end in part in the floor of the island and to continue in part to the parietal operculum of the island. Some fibers continued more dorsalward and entered the adjacent postcentral gyrus of the parietal lobe. Some degenerated fibers could be traced into the corpus callosum, but their termination could not be determined in the material. No degenerated fibers could be followed caudal. ward to area 19 from this lesion.

From the more rostral portions of the lesion on the superior temporal gyrus, scant degenerated granules could be traced mediad across the capsula externa, to a sublenticular position. Some degenerated fibers passed through the inferior caudal aspects of the putamen to a position medial to the putamen, where they were joined by fibers from the sublenticular area. From here, fibers (temporo-pontine tract) could be traced farther rostralward where they then swung medially into the lateral aspects of the cerebral peduncle; 
they could be followed as far as the pons. Some fibers (cortico-geniculate tract) swung mediad, passing back and down to the rostrolateral aspect of the medial geniculate nucleus. These were few in number and appeared to end at this level. Degenerated fascicles (cortico-thalamic tract), running slightly caudal to the temporo-pontine fibers, turned through the internal capsule, then swung up into the ventral nucleus of the thalamus at its caudal end. Other degenerated fibers coursed ventrally into the region of the decussation of the brachium conjunctivum, where a few of them appeared to cross. At slightly more caudal levels, they then turned dorsad into the medial longitudinal fasciculus, where they could be traced to the level of the abducens nucleus.

From the more caudal aspects of the lesion on the left superior temporal gyrus, fibers passed through the posterior limb of the internal capsule, to the lateral border of the pulvinar, where degenerated fibers (cortico-tegmental tract, temporal division) turned into the superior colliculus. Beginning at a point lateral to the tecto-pontine fibers, degenerated fascicles ran caudad and ventrad to the medial lemniscus; a few swung into the tegmentum of the midbrain, where they appeared to synapse. At this point the fibers in the region of the medial lemniscus were joined by bundles (possibly a cortical aberrant tract) swinging dorsad from the lateral aspect of the peduncle (presumably from the temporo-pontine system) and from this point these two paths were indistinguishable. Their termination could not be ascertained in this material.

\section{Monkey no. 6}

This young female monkey learned the finer auditory discrimination test after 800 trials. Then, on January 23, 1950, a right temporal craniotomy was done over the superior temporal gyrus. Stimulation of this gyrus (fig. 4) in the area intermediate between $F$ and $G$ resulted in elevation of the upper lip and closing of the eyelid on the side of stimu- 
lation. More posteriorly, at $\mathrm{F}$, there was conjugate deviation of the eyes to the opposite side. A surgical lesion was made in the superior temporal gyrus and in the posterior portion of the middle temporal gyrus as indicated in figure 13. Postoperatively the animal showed no loss of ability to perform the auditory discrimination test. On January 30, 1950, a left temporal eraniotomy was performed over the superior temporal gyrus. Stimulation at the level of the central fissure, at $G$ (fig. 13), resulted in a tensing of the neck muscles, a flexion of the upper and lower extremities; in the intermediate areas between $\mathrm{F}$ and $\mathrm{G}$, a turning of the head to the right, an elevation of the right upper lip and a blinking of the right eyelid; and at the level of F, conjugate deviation of the eyes to the opposite side. A surgical lesion was made in the superior temporal gyrus as indicated in figure 13. Postoperatively the animal showed no loss of memory for the auditory discrimination test after the bilateral symmetrical lesions.

At postmortem, and as seen in the Marchi preparations, the surgical lesion involved bilaterally the exposed cortex of the superior temporal gyrus and of the middle temporal gyrus in the caudal parts of the lesion. From the more rostral portions of the lesion in the left superior temporal gyrus, degeneration granules could be traced across the superior temporal gyrus. Some degenerated fibers turned inward into the temporal operculum of the island; others swung dorsad in the capsula extrema ending in the floor of the island and its parietal operculum (fig. 17). Some of the degenerated fibers were seen to pass through the capsula extrema where they were joined by degenerated fascicles from the capsula externa. These latter extended into the parietal lobe; others, more medially, entered the corpus callosum. Fine degeneration granules were found in the middle and inferior temporal gyri. In the most caudal portions of the lesion in area 22 , the major passage of degenerated fibers was to the adjacent area 19. In the area where the lesion involved the middle temporal gyrus, degenerated fibers passed from it into the inferior temporal gyrus. 
From the more rostral portion of the lesion on the left superior temporal gyrus, the degeneration granules could be traced across the external capsule to a sublenticular position. Some degenerated fibers could be followed through the inferior caudal aspect of the putamen. From this sublenticular position fibers proceeded forward, medial to the putamen, and then passed through the auditory radiations to the medial geniculate nucleus (fig. 17). Here a considerable number of degenerated fascicles ended (cortico-geniculate fibers), others turned mediad and caudad along the medial aspect of the medial geniculate body to inferior collicular levels (corticotectal tract, auditory division). Still other degenerated fibers, coursing behind the entrance of the temporo-pontine bundles into the peduncle, descended through the internal capsule. Some of these fibers (cortico-thalamic tract) ended in the ventral nucleus of the dorsal thalamus and others passed more medially and caudally to the region of the interstitial nucleus of the medial longitudinal fasciculus. Degenerated fascicles (cortico-rubral tract) entered the lateral aspects of the large-celled part of the red nucleus (fig. 17). Finally, some degenerated fibers proceeded through the tegmentum (nucleus mesencephalicus profundus), some synapsing, to the region of the decussation of the brachium conjunctivum and then swung up into the medial longitudinal fasciculus, wherein they continued in a caudal direction.

From the more caudal aspect of the lesion on the left superior temporal gyrus, fibers descended through the posterior limb of the internal capsule to the lateral border of the pulvinar, from which position degenerated granules could be followed to the superior colliculus (fig. 18). At this point, lateral to the tecto-pontine and dorsal to the auditory division of the cortico-tectal tract, the cortico-tegmental tract, temporal division, interdigitated with the tecto-pontine fibers to reach the medial aspects of the medial lemniscus. In the pons, degenerated fibers swung dorsad into the medial lemniscus, presumably from the cortico-pontine system. These two tracts then became indistinguishable. Slightly caudad, 
some of these fibers entered the abducens nucleus, and there is presumptive evidence of a termination of some of them in the motor nucleus of VII.

\section{Monkey no. 7}

On March 2, 1950, a left temporo-occipital craniotomy was performed over area 19 in areas C and D (fig. 4) of a young female monkey. On exposing this area, a large vein was again encountered which passed through the inferior occipital sulcus and entered a dural sinus in the caudal aspects of the wound. The presence of the vessel hampered somewhat the remainder of the experiment. Stimulation at $\mathrm{C}$ resulted in left facial movements, characterized by retraction of the upper lip and movements of the eyelid. At level D, movements of the shoulders and forearms bilaterally and, at level $\mathrm{E}$ on the basal surface, flexion of both knees and extension movements of both feet were obtained on stimulation. A cauterizing lesion was made blindly in the areas of stimulation (fig. 14). The postoperative course was entirely uneventful.

Postmortem examination on March 16 revealed that the cortical lesion on the basal surface of the hemisphere extended rostrally from the area where the movements had been elicited to the adjoining inferior temporal gyrus. The Marchi material showed that, in addition to the cortical lesion (fig. 14), there was a degeneration of the hippocampus and of the hippocampal gyrus from its most caudal portion forward to the level of the mammillary body. Degenerated fibers could be traced from the fimbria into the fornix (fig. 20), passing forward in all portions of the left fornix. Some of these fibers ended in the ventral part of the left mammillary body and others continued caudally in the stria medullaris to the level of the habenula.

There was an extension of the midportion of the lesion dorsalward into the posterior limb of the internal capsule. The lesion here involved some of the external cortico-tectal fibers, which could be traced candally, lateral to the lateral 
geniculate nucleus, along the ventrolateral surface of the pulvinar. The fibers shifted mediad and dorsad through the pulvinar to reach the lateral border of the superior colliculus, being the most caudal fibers to enter that midbrain area (fig. $20)$. The fibers distributed to the most superficial layers of the superior colliculus.

The evact origin of the fibers from the lesion in the occipitotemporal cortex could not be determined with certainty in this case. From the lesion, some degenerated fibers swung into the putamen, others passed from the more rostral portion into the capsula extrema to terminate in the middle and superior temporal gyri, and still others, from the caudal end of the lesion, entered the posterior limb of the internal capsule to reach area 19 above the inferior occipital sulcus. A considerable number of degenerated fibers could be traced through the corpus callosum to the opposite hemisphere. Degenerated fascicles coursed forward along with the visual radiations; some bundles (internal cortico-tectal tract) reached the lateral border of the pulvinar, crossed it, and entered the superior colliculus deep to the stratum opticum. A marked degeneration was seen in nucleus pulvinaris medialis. Degenerated fascicles ran over the top of the lateral geniculate nucleus (fig. 19), caudal to the temporo-pontine tract, to the lateral border of the red nucleus and the tegmentum of the midbrain. Some degenerated fibers entered the lateral portion of the substantia nigra. At more rostral levels, other degenerated fibers (temporo-pontine tract) coursed, medial to the putamen, into the lateral portion of the peduncle.

\section{RESULTS OF CORTICAL STIMULATION}

The series of experiments carried out in this report were designed to investigate the functions of lower area 19 and the part of area 22 immediately adjacent to the primary projection of the auditory system.

Under ether anesthesia, the lower area 19 was exposed and its various portions stimulated. For descriptive purposes 
these portions have been termed: area 19-C (fig. 4), situated about $1 \mathrm{~cm}$ below the inferior occipital sulcus; $19-\mathrm{D}$, the area beneath 19-C at the junction of the lateral and basal surfaces of the occipital lobe; and 19-E, the basal surface. It will be noted that $\mathrm{E}$ has been placed on the diagram for purposes of convenience; actually, it is not visible on the lateral view of the macaque brain, being limited entirely to the basal surface. Under relatively light ether anesthesia, it was possible to elicit, from area $\mathrm{C}$, facial movements, which in some instances were bilateral and in other instances unilateral. In this investigation, at $\mathrm{D}$, a turning of the head to the opposite side and, in one instance, complex movements of the upper extremities were obtained. Stimulation of the basal surface (E) elicited complex movements of the lower extremities and trunk muscles.

Under similar circumstances, the part of area 22 which is immediately adjacent to the auditory cortex was exposed. In this report, $F$ designates the more caudal portions and $G$ the more rostral portions of area 22 . Under relatively light anesthesia it was posible to elicit, on cortical stimulation of area $22-\mathrm{F}$, conjugate deviation of the eyes to the opposite side. From the more rostral portions of $22-G$, complex movements of the extremities were obtained on stimulation. In the intervening area, bilateral movements of the face or, in certain instances, unilateral movements of the face, as well as a turning of the head to the opposite side, were obtained. In this adversive field the movements appeared to be elicited from more specific areas of the cortex than had previously been identified (C. and O. Vogt, '26). Under the circumstances of the present experiments, an exact analysis of the movements elicited was not possible. The ideal conditions were those in which the animal had just lost voluntary control of the eyes, since in deeper stages of anesthesia the movements were abolished.

Ferrier (1876), in electrical studies of area 22, described a turning of the head and eyes to the opposite side, pricking up of the opposite ear, and dilatation of the pupils. Others 
(Schäfer, 1888; C. and O. Vogt, '26; Hines, '43) have described similar movements. In the present study the movements appeared to be elicited from more specific areas than the diffuse fields related to these movements as indicated in the map of the Vogts ('26). Foerster ('36), in electrical stimulation of the superior temporal gyrus in man, described turning of the head, trunk, and extremities, with or without deviation of the eyes, toward the opposite side. Penfield and Frickson ('41, loc. cit., p. 54-56) found that stimulation in this region in man produced sensations of buzzing sounds, dreams in which the patient heard music or voices, and other hallucination phenomena. In a case history of an epileptic with an old traumatic lesion of area 22, Foerster ('36) reported the man's attacks as beginning with an acoustic aura followed by a tonic-clonic mass spasm with rotation of the eyes, the head, and the body away from the side of the lesion. At the time of operation, Foerster was able to reproduce these same symptoms by stimulation of the lesion.

Ferrier (1876) found that stimulation beneath the inferior occipital sulcus in area 19 of the monkey caused uneasy movements of the hind legs and tail and that the animal looked toward the opposite hind leg, occasionally uttering a plaintive cry. On their map, the Vogts ('26) designated this area beneath the inferior occipital fissure as $19 \mathrm{~b}$ and produced adversive movements of the trunk and the appendages of the monkey by electrical stimulation of this area. The site of origin of these movements appears to be more circumscribed than was indicated on the map of the Vogts ('26). No description of electrical stimulation of this area in man was encountered in the literature.

\section{RESULTS OF AUDITORY AND VISUAL DISCRIMINATION TESTS}

In the present report a series of auditory and visual discrimination tests were designed to investigate the higher functions of the temporal and occipital cortices. In the preliminary phases of this investigation, visual and anditory 
box discrimination tests were employed in the experiments. After partial ablation of the temporal or occipital cortex, no permanent changes were noted in the ability of the animals to discriminate in these tests. In the later phases of the investigation the animals were subjected to a finer auditory discrimination test. No loss was noted in the animal's ability to perform the test after unilateral or bilateral ablation of the cortex adjacent to the primary auditory area on the superior temporal gyrus. It has been the author's experience that a much more extensive and prolonged training period was required to develop an animal's ability to perform the auditory discrimination test after such operations. This was especially apparent in the finer auditory discrimination test in which the preoperative period required 1000 or more trials before the animal developed the ability to perform the test. Nielsen ('47, loc. cit., p. 119-123) concluded, from his studies on man, that bilateral lesions limited to the superior temporal gyrus produced a patient who was able to hear, yet was not able to recognize the significance of the sounds. The present investigation would indicate that the macaque is able to perform a discrimination test in the absence of the exposed cortex of area 22 immediately adjacent to the primary auditory area.

\section{COMMENTS}

The cytoarchitecture of the cortex may be a reflection of particular functions. The granular layer is especially well developed in those regions which receive a rich supply of fibers from subcortical centers. The supragranular layers are related particularly, though perhaps not exclusively, to the intracortical connections, and many corticifugal fibers arise from the infragranular layers (Ariëns Kappers, Huber, Crosby, '36).

Possible changes in behavior following large lesions of the temporal lobe have been considered by various observers, as Jacobsen and Elder ('36) and Bucy and Klüver ('40). Following extensive symmetrical ablations of the temporal lobe 
a trained baboon showed an essentially normal behavior and a normal reaction in a delayed reaction test. Bucy and Klüver ('40) reported a syndrome of psychic blindness following bilateral temporal lobectomy. The animals could not recognize the nature of objects except by examining them by taste and smell. They also showed changes in sexual behavior and dietary habits, with a strong tendency to note and to react to every visual stimulus.

The monkey has virtually no serviceable vision after bilateral removal of the occipital lobes; the animal cannot discriminate between objects of different sizes or varying brightnesses, but reacts only to the total quantity of light (Klüver, '41). Ades ('46) demonstrated that learned visual form discrimination was abolished by one stage bilateral extirpation of areas 18 and 19, but could be relearned in approximately the same number of trials as were required for the original learning. Ades and Raab ('49) found that if training was carried on between operations, seriatim destruction of areas 18 and 19 produced no habit loss after either operation; however, subsequent bitemporal decortication produced an animal which could not relearn the test with prolonged training. Bilateral removal of areas 18 and 19 permanently abolished the ability to carry out the form discrimination test, although both animals readily learned a simple brightness discrimination test in the same apparatus. No changes in behavior were noted in the animals examined in the experiments reported here in visual and auditory discrimination tests after partial unilateral and bilateral ablations of the auditory and visual association areas.

\section{ANATOMICAL RESULTS}

To facilitate an understanding of certain anatomical pathways described in this paper, a brief review of the terminology introduced by Crosby and Henderson ('48) will be given as it forms the basis of the terminology used here. From the occipital lobe they recognized two separate systems of fibers in the internal cortico-tectal system which they termed the 
occipital division and the preoccipital division. Each of the divisions was subdivided further into dorsal and ventral parts depending upon whether it arose from upper or lower portions of the occipital or preoccipital area. From the temporal lobe, in the area ventral to the caudal third of the superior temporal sulcus, they described an external cortico-tectal system with a distinct anatomical distribution on the superior colliculus, and from the occipital lobe a cortico-tegmental system, which Crosby ('50) has later followed to the level of the contralateral abducens nucleus. In the present material, a cortico-tegmental tract was described and designated the temporal division to distinguish this system more clearly from the occipital division.

\section{Cortico-tectal tract, auditory division}

From area 22, fibers could be traced in the degenerated material across the white matter of the hemisphere and through the capsula extrema, the claustrum, and capsula externa to the sublenticular portion of the internal capsule, where the fibers were seen to intermingle with the auditory radiations. Fibers then proceeded caudad, ventrad, and mediad until the medial geniculate nucleus was reached, at which point the fibers diminished (cortico-geniculate tract). Some fibers (cortico-tectal tract, auditory division) continued along the medial aspect of the medial geniculate nucleus and the under border of the superior colliculus to the inferior colliculus. Following ablation studies in macaque in the more rostral aspects of area 22, Mettler ('35) described degenerated fibers in the region of the rostral pole of the inferior colliculus. Riley ('43) indicated fibers from cortical auditory areas to the inferior colliculus and the medial geniculate nucleus in man.

\section{Cortico-tegmental tract, temporal division}

From area 22-F fibers could be traced across the white matter of the hemisphere into the posterior limb of the in- 
ternal capsule, where they then crossed medial to the lateral border of the pulvinar. They passed across the pulvinar where the degenerated fibers accumulated at the junction of the pulvinar and the superior colliculus, dorsal to the degenerated fibers of the cortico-tectal tract, auditory division, to join the occipital division of the cortico-tegmental fibers. Hirasawa, Okano, and Kamio ('38) found some entering the stratum zonale and stratum opticum of the superior colliculus. Fibers appeared to swing into the medial longitudinal fasciculus; others proceeded backward and downward into the medial portions of the med:al lemniscus, being joined by fascicles from the peduncle (possibly cortico-bulbar) which join the medial lemn'scus at pons levels. Slightly caudad in the material, some fibers entered the 6 th nucleus.

\section{Cortico-striate system}

From the region below the inferior occipital sulcus in area 19 , degenerated fibers could be traced across the white matter of the hemisphere forward with the visual radiations, then into the posterior part of the corpus callosum; others (corticostriate tract, ventral occipital division) continued forward, lateral to the visual radiations at the caudal level of the lateral geniculate nucleus, to enter the caudal and ventral aspects of the putamen. From the more rostral portions of the lesion on the superior temporal gyrus, degenerated fibers (cortico-striate tract, temporal division) passed across the external capsule to the inferior caudal portions of the putamen. From the lesion in the internal capsule and adjacent parietal operculum, fibers (cortico-striate tract, parietal division), presumably of parietal origin, could be traced into the putamen.

\section{Cortico-nigral tract}

From the lesions on the more rostral portions of the superior temporal gyrus, degenerated fibers could be followed sublenticularly into the lateral aspects of the substantia nigra, passing through the internal capsule. These constitute the 
cortico-nigral tract, temporal division (Bucy and Klüver, '40; Hirasawa, Okano, and Kamio, '38). Koikegami and Imogawa ('36) have described fibers (cortico-nigral tract, dorsal occipital division) from area 19 above the inferior occipital sulcus to substantia nigra. There was presumptive evidence, in the material studied, of a cortico-nigral system of fibers (cortico-nigral tract, ventral occipital division) from area 19 beneath the inferior occipital sulcus to the substantia nigra.

\section{Cortico-rubral tract}

From the lesions in the more rostral portions of the superior temporal gyrus, fibers (cortico-rubral tract, temporal division) could be traced sublenticularly through the internal capsule to the lateral aspect of the large-celled part of the red nucleus (Mettler, '35; Hirasawa, Okano, and Kamio, '38) and to the tegmentum of the midbrain. Some fibers continued more ventrally into the area of the brachium conjunctivum, where a few fascicles presumably crossed; these fibers then swung upward into the medial longitudinal fasciculus. From the lesion in the internal capsule and adjacent parietal operculum, fibers could be followed through the internal capsule then slightly rostrad to the auditory radiations, to reach the lateral portion of the red nucleus, large-celled part. These fibers were presumably of parietal origin. Archambault ('14) has described fiber connections from the Sylvian and Rolandic opercula and island of Reil to the middle segment of the red nucleus in man. Koikegami and Imogawa ('36) have followed fibers from area 19 above the inferior occipital sulcus to the red nucleus (cortico-rubral tract, dorsal occipital division). From the area beneath the inferior occipital sulcus in area 19, fibers (cortico-rubral tract, ventral occipital division) crossed the white matter of the gyrus to pass forward in the visual radiations. Then they passed over the dorsal surface of the lateral geniculate nucleus, to enter the tegmentum of the midbrain, where they ended in the tegmental gray and in the large-celled part of the red nucleus. From the infero-in- 
ternal surface of the human temporo-occipital area, Archambault ('14) described fibers to the red nucleus.

\section{Cortico-pontine tract}

From the superior temporal gyrus degenerated fascicles (cortico-pontine tract, temporal division) could be traced across the white matter of this gyrus and underneath the lenticular nucleus to join fibers from the other temporal gyri. The united bundles passed sublenticularly into the outer portion of the cerebral peduncle, dorsal and lateral to the parietooccipito-pontine fibers. In this position they could be followed to pons levels, presumably to synapse with neurons which discharge by way of the brachium pontis to the cerebellum. Sunderland ('40), in his review of the literature and in his experimental material, described fibers to the pons from the temporal, the parietal, and the occipital lobes of the macaque.

\section{Cortico-thalamic tract}

From the lesions on the superior temporal gyrus, degenerated fibers could be traced sublenticularly and through the islets of the putamen to the ventral nucleus of the thalamus. Hirasawa, Okano, and Kamio ('38) have described these degenerated fibers, as well as fine degenerations to the lateral nucleus of the thalamus. From the lesion in the thalamus, intermediate between lateral and ventral thalamic nuclei, degenerated fibers (a thalamo-cortical tract) could be followed sublenticularly, and through the putamen, to the superior temporal gyrus. The exact termination of these bundles was not determined. Koikegami and Imogawa ('36) have described degenerated fibers from area 19 above the inferior occipital sulcus to the ventral and lateral nuclei of the thalamus.

\section{Discharge paths from subcortical centers}

Anatomically, there are well recognized paths from the subcortical centers to the lower brainstem and spinal cord. A 
brief reference will be made to those pathways pertinent to an understanding of the problem at hand. The major discharge path - the comb bundle - of the substantia nigra courses forward to the globus pallidus and possibly to the putamen. From the putamen, fascicles pass medially to the globus pallidus, and from here run caudally to the red nucleus, the tegmental gray, the interstitial nucleus, and the nucleus of Darkschewitch by way of the lenticular fasciculus. Some fibers distribute to the nucleus mesencephalicus profundus pars lateralis caudalis by way of the ansa lenticularis; others pass in relation to the subthalamic nucleus to reach the lateral aspect of the tegmental gray of the midbrain. From these various regions paths descend as rubro-spinal, caudal rubrospinal, and tegmento-spinal paths to the spinal cord; other fibers are distributed to the brainstem by way of the medial longitudinal fasciculus and the tegmento-bulbar system (Woodburne, Crosby, and McCotter, '46).

\section{SUMMARY}

1. In the auditory (area 22) and visual (area 19) association areas of Macaca mulatta, there is a definite pattern of eye movements with complex movements of face, neck, and trunk on electrical stimulation.

2. From the part of area 19 (Crosby, '50) and area 22, stimulation of which produced horizontal deviation of the eyes, fibers (cortico-tegmental, occipital division and corticotegmental, temporal division) can be traced through the tegmentum of the midbrain to the abducens nucleus.

3. The movements of the eyes in other planes are mediated over fiber systems (cortico-tectal tract, preoccipital division and external cortico-tectal tract) which pass to the superior colliculus from area 19 and the auditory area.

4. From those portions of area 19 and area 22, stimulation of which produced complex movements of face, neck, and trunk, fiber paths can be traced to basal ganglia, red nucleus, substantia nigra, and tegmentum of the midbrain. 


\section{LITERATURE CITED}

ADEs, H. W. 1946 Effect of extirpation of parastriate cortex on learned visual discriminations in monkeys. J. Neuropath. and Exp. Neur., $5: 60-65$.

Ades, H. W., AND D. H. RAAB 1949 Effect of preoceipital and temporal decortication on learned visual diserimination in monkeys. J. Neurophysiol., 12: 101-108.

Archambault, L. 1914 The cortical connections of the red nucleus. Albany M. Ann., 35: 527-549.

AriëNs Kappers, C. U., G. C. Huber ANd E. C. CrosbY 1936 The comparative anatomy of the nervous system of vertebrates, including man. Macmillan Company, New York. 2 vols.

Bonin, G. v., AND P. Balley 1947 The neocortex of Macaca mulatta. Ill. Monographs in Med. Scienees. Univ. of Ill. Press, Urbana, 5 (no. 4) : 163 p.

Bucx, P. C., AND H. KLÜVER 1940 Anatomie ehanges secondary to temporal lobectomy. Areh. Neur. and Psychiat., 44: 1142-1146.

Crossx, E. C. 1950 The application of neuroanatomical data to the diagnosis of selected neurosurgical and neurological eases. J. Neurosurg., 7 : $566-583$.

Crosby, E. C., ANd J. W. Henderson 1948 The mammalian midbrain and isthmus region. Part II. Fiber connections of the superior colliculus. B. Pathways concerned in automatic eye movements. J. Comp. Neur., $88: 53-92$.

FrRrier, D. 1876 The functions of the brain. Smith, Elder and Co., London, $323 \mathrm{p}$.

Foerster, O. 1936 Motorische Felder und Bahnen. In vol. 6 of Handbuch der Neurologie (edited by $O$. Bumke and O. Foerster). Julius Springer, Berlin, $1153 \mathrm{p}$.

HINES, M. 1943 Control of movements by the cerebral eartex in primates. Biol. Rev., 18: 1-31.

1944 Significance of the precentral motor cortex. Ch. XVIII (pp. 459-494) in Precentral motor eortex (edited by P. C. Bucy). Ill. Monographs in Med. Sciences, 4. Univ. of Ill. Press, Urbana.

Hirasawa, K., S. OKano, Und S. Kamio 1938 Beitrag zur Kenntnis über die corticalen extrapyramidalen Fasern aus der Area temporalis superior (Area 22) beim Affen. Ztschr. f. mikr.-anat. Forsehg., 44: 74-84.

JACOBSEN, C. F., AND J. H. EldDER 1936 Studies of cerebral function in primates. Part II. The effect of temporal lobe lesions " on delayed response in monkeys. Comp. Psychol. Monogr., 63: 61-65.

KL Üver, H. 1933 Behavior mechanisms in monkeys. Univ. of Chicago Press, Chicago. $387 \mathrm{p}$.

1941 Visual functions after removal of the oceipital lobes. $J$. Psychol., 11: 23-45.

KoIkegami, H., und M. Imogawa 1936 Über die Fasern, insbesondere die kortikalen extrapyramidalen aus der Area 19a der Grosshirnrinde beim Affen. Morphol. Jahrb., 77: 587-604.

MCCULLOCH, W. S. 1944 The functional organization of the cerebral cortex. Physiol. Rev., 94: 390-407. 
METTLER, F. A. 1935 Corticifugal fiber connections of the cortex of Macaca mulatta. The temporal region. J. Comp. Neur., 63: 25-47.

Niglsen, J. M. 1947 Agnosia, apraxia, aphasia; their value in cerebral localization. P. B. Hoeber, Inc., New York, London, 292 p.

Penfield, W., and T. C. ERICkson 1941 Epilepsy and cerebral localization. Charles C Thomas. Springfield, Ill. $623 \mathrm{p}$.

Polriar, L. J. 1951 Anatomical and experimental studies of the temporal lobe of the macaque. J. Comp. Neur., to be published.

RILEY, H. A. 1943 An atlas of the basal ganglia, brain stem, and spinal cord. Williams and Wilkins Co., Baltimore, $708 \mathrm{p}$.

SCHÄFER, E. A. 1888 A comparison of the latency periods of the ocular museles on excitation of the frontal and occipito-temporal regions of the brain. Proc. Roy. Soc., 43: 411-412.

Sмiтн, W. K. 1944 The frontal eye fields. Ch. XII (pp. 307-342) in Precentral motor cortex (edited by P. C. Bucy). Ill. Monographs in Med. Sciences, 4. Univ. of Ill, Press, Urbana.

SUNDERLAND, S. 1940 The projection of the cerebral cortex on the pons and cerebellum in the macaque monkey. J. Anat., 74: 201-226.

Swank, R. L., AND H. A. DavenpoRT 1935 Chlorate-osmic-formalin method for staining degenerating myelin. Stain Technology, 10: 87-90.

VoGT, C., AND O. VOGT 1926 Die vergleichend-architektonische und die vergleichend-reizphysiologische Felderung der Grosshirnrinde unter besonderer Berücksichtigung der mensehlichen. Naturwissenschaften, 14: 1190-1194.

Woodburne, R. T., E. C. Crosby And R. E. McCotrer 1946 The mammalian midbrain and isthmus regions. Part II. The fiber connections. A. The relations of the tegmentum of the midbrain with the basal ganglia in Macaca mulatta. J. Comp. Neur., 85: 67-92. 


\section{PLATES}

\section{ABBREVIATIONS}

aq., aqueduct.

aud. a., auditory area.

aud. rad., auditory radiations.

cal. f., calcarine fissure.

caud. n., caudate nucleus.

cereb., cerebellum.

corp. cal., corpus callosum.

cort. rub. tr., eortico-rubral tract.

cort. tect. tr. aud. div., cortico-tectal tract, auditory division.

cort. teg. tr. t. div, eortico-tegmental tract, temporal division.

ext. cort. tect. tr., external corticotectal tract.

F., fornix.

fim., fimbria.

hjp. g., hippocampal gyrus.

I., island.

L., lesion.

lat. gen. n., lateral geniculate nucleus.

lat. thal. n., lateral thalamic nucleus.

M., degenerated fibers passing from area 22.

med. gen. n., medial genienlate nueleus. $\mathrm{N}$, degenerated fibers passing to area 22. n. pul. med., nucleus pulvinar medialis.

o., degenerated fibers in capsula extrema.

op. tr., optie tract.

pariet. pont. tr., parieto-pontine tract. ped. inf. col., peduncle of inferior colliculus.

pul., pulvinar.

put., putamen.

sen, rad., sensory radiations.

sub. nig., substantia nigra.

tect. pont. tr., teeto-pontine tract.

tect. sup. eol., tectum of superior colliculus.

temp. pont. tr., temporo-pontine tract. vent. thal. $n$. , ventral thalamic nucleus. vis. rad., visual radiations.

4 , area 4

6 , area 6

8 , area 8.

18 , area 18.

19 , area 19.

21 , area 21.

22 , area 22.

\section{PLATE 1}

\section{EXPLANATION OF FIGURES}

1 Photograph of boxes used in diserimination test.

2 Photograph of the double set of doors as seen from the interior of the test cage used in the finer auditory discrimination test.

3 Photograph of the master switch panel on the back of the test cage as seen by the examiner. 

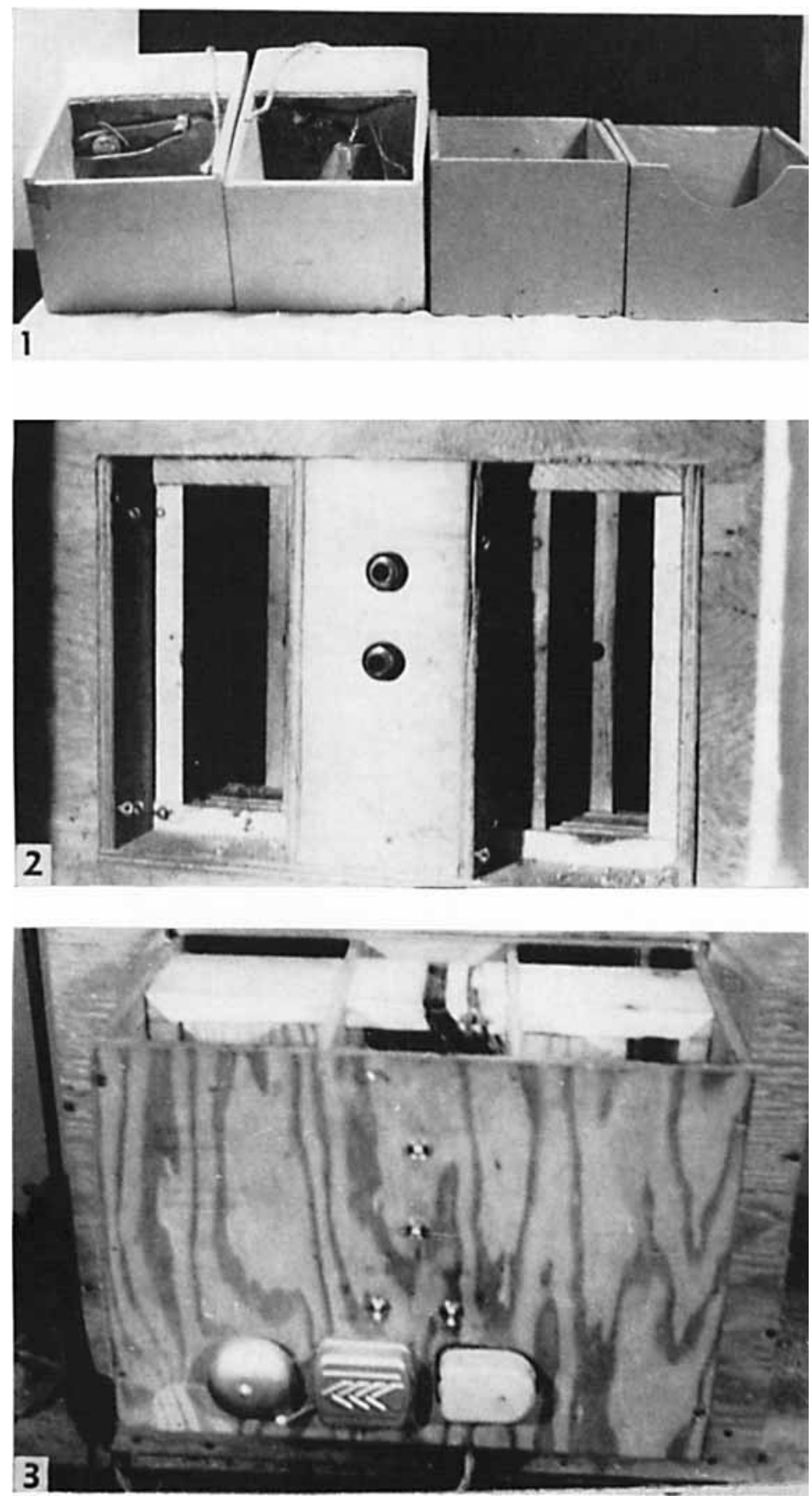


\section{PLATL 2}

\section{EXPLANATION OF FIGURES}

4 Photograph of the left side of the brain of Macaca mulatta.

5 Monkey no. 1. Appearance of the lesion in the left hemisphere at autopsy.

6 Monkey no. 1. Appearance of the lesion in the right hemisphere at autopsy.

7 Monkey no. 2. Symmetrical operative lesions made in first and second operations.

8 Monkey no. 2. Symmetrical operative lesions made in third operation. 


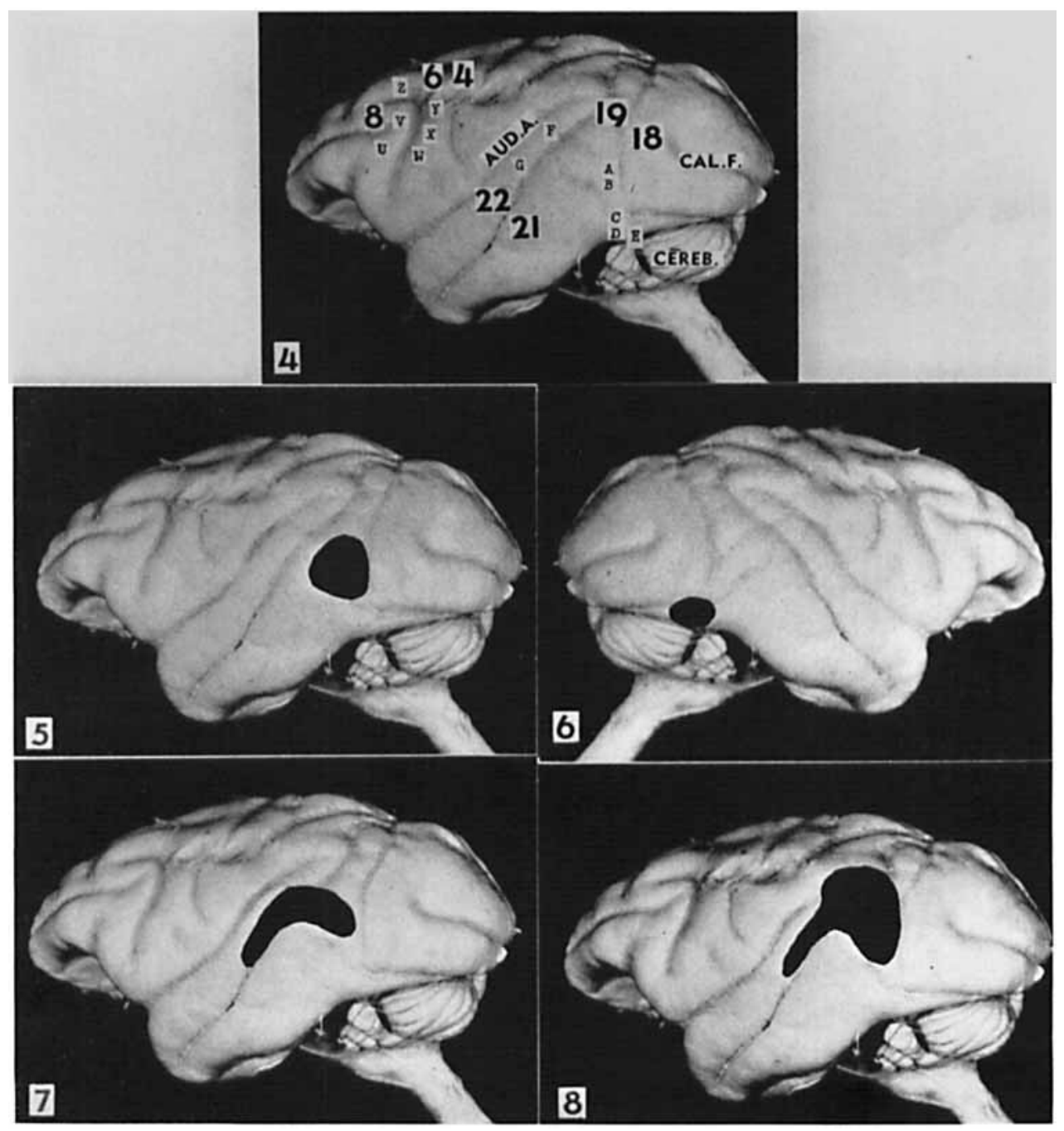


PLATE 3

EXPTAANATLON OF FLGURES

9 Monkey no. 3. Appearance of lesion in the left hemisphere at autopsy.

10 Monkey no. 3. Appearanee of lesion in the right hemisphere at autopsy.

11 Monkey no. 4. Appearance at autopsy of lesion in the left hemisphere.

12 Monkey no. 5. Appearanc at autopsy of lesion in right hemisphere.

13 Monkey no. 6. Appearance at autopsy of the symmetrical lesions on the superior temporal gyrus.

14 Monkey no. 7. Appearance of lesion in left hemisphere which extends medially on the basal surface of the occipital lobe. 


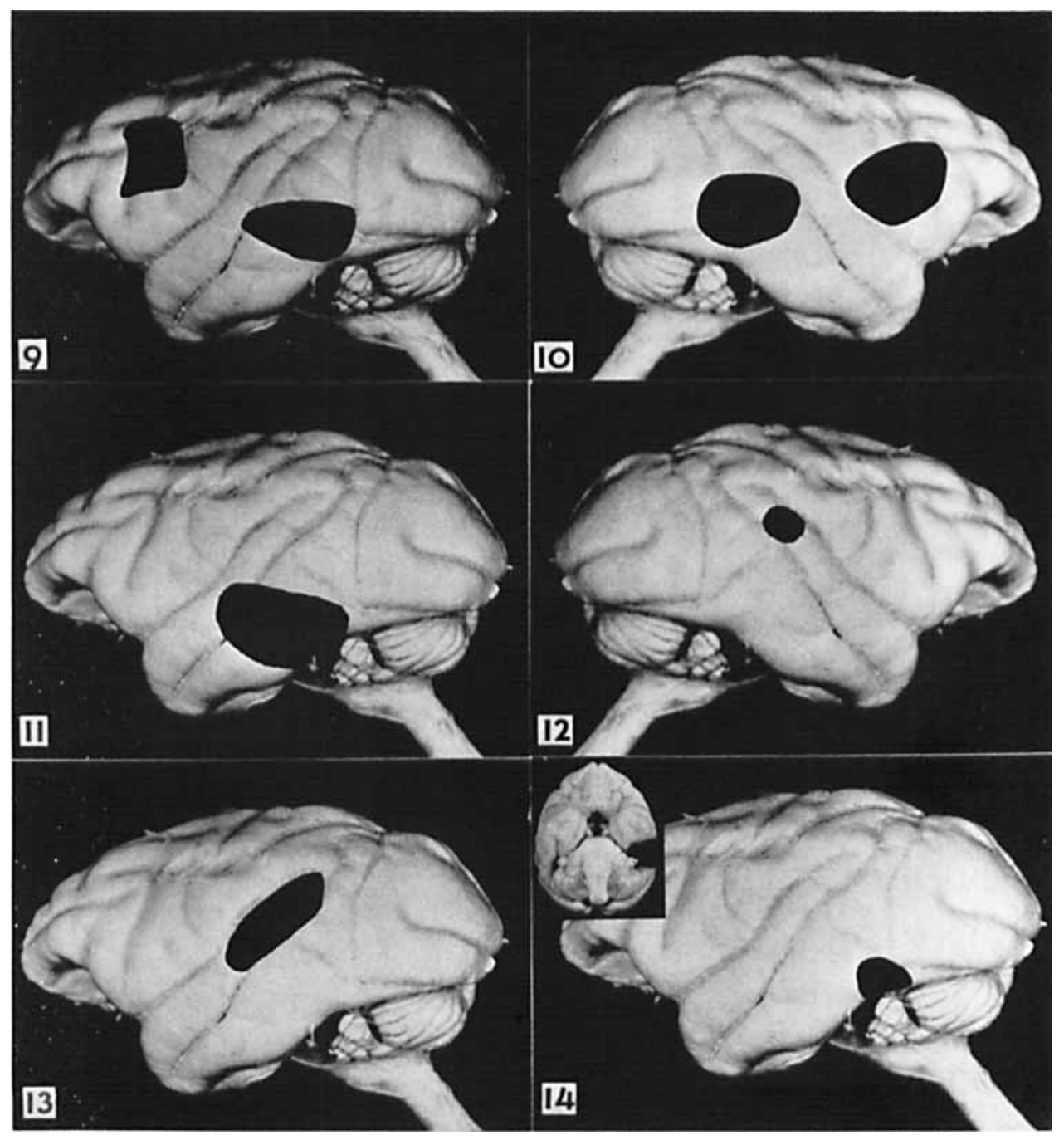


PLATE 4

FXPLANATION OF FIGURES

15 Ihotomicrograph of section through the left pulvinar nucleus from monkey no. 4.

16 Photomicrograph of section through the vascular lesion in the right thalamus and parietal operculum in monkey no. 4. 

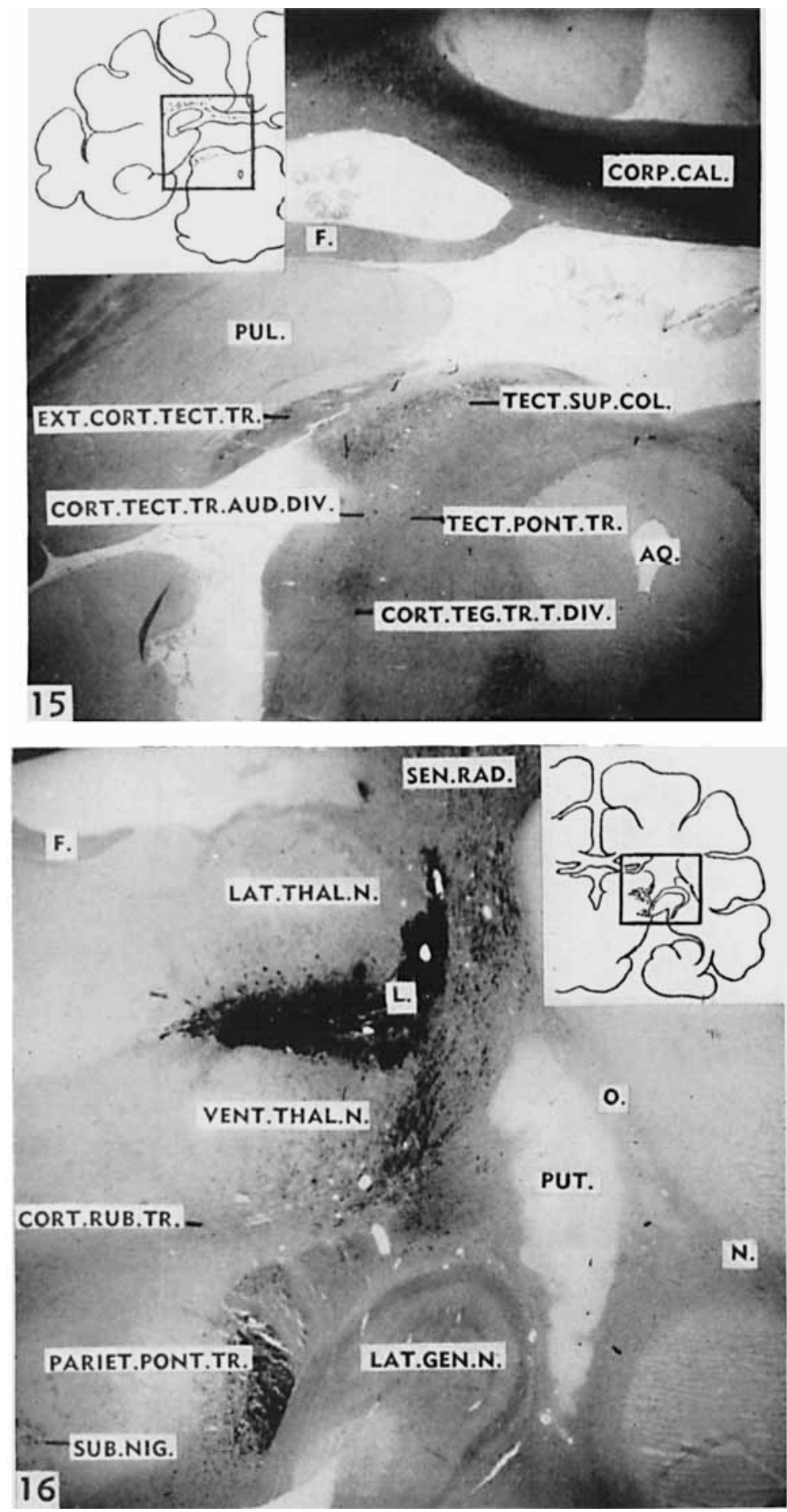


\section{PLATE 5}

EXPLANAIION OF FIGURES

17 Photomierograph of section through the right auditory radiations from monkey joo. 6.

18 Photomicrograph of section through the left pulvinar nucleus from monkey no. 6 . 

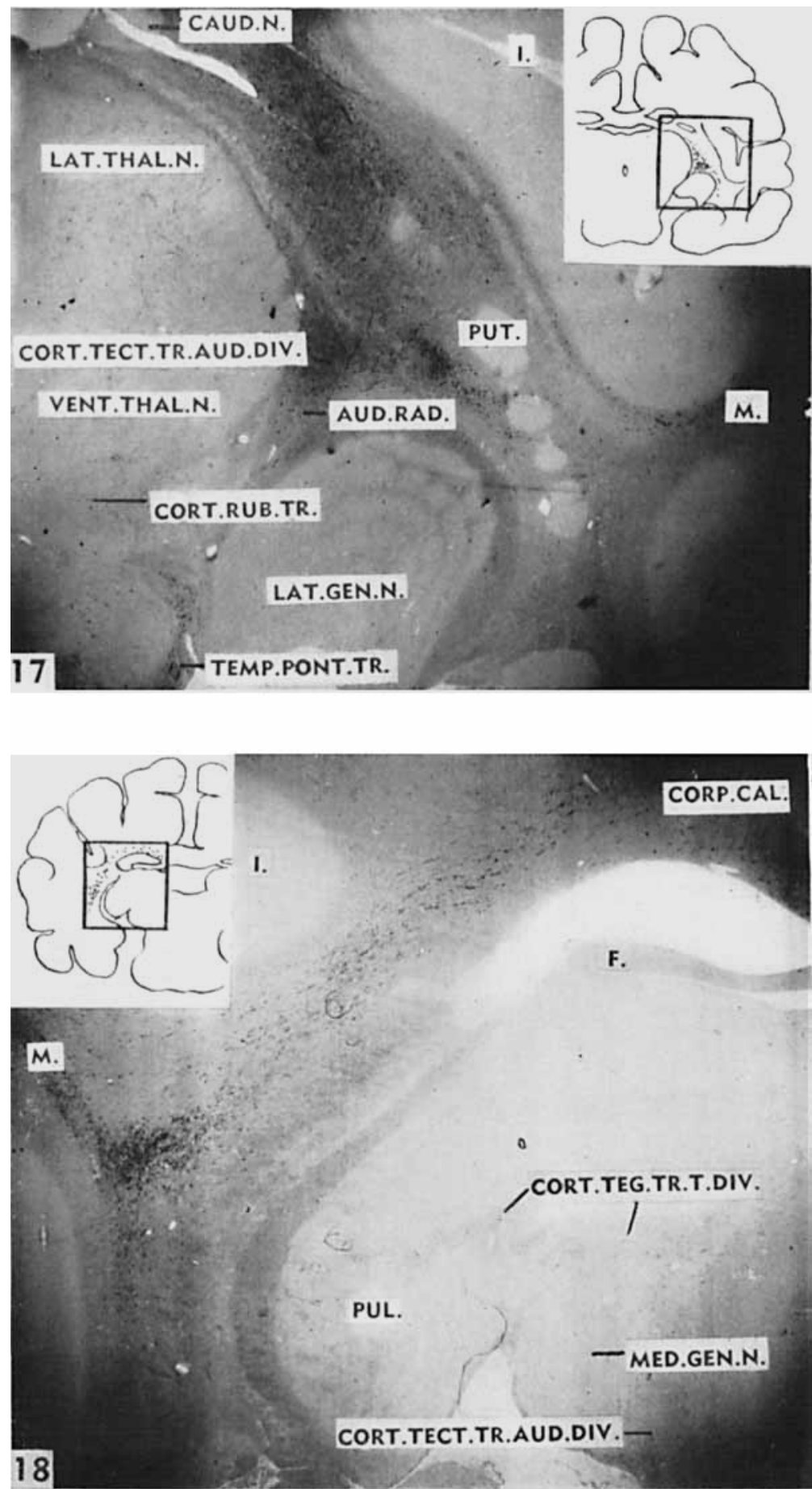


\section{PLATE 6}

\section{EXPLANATION OF FIGTTRES}

19 Photomicrograph of section through the left lateral geniculate nueleus from monkey no. 7 .

20 Photomicrograph of section through the left pulvinar nucleus from monkcy no. 7 . 


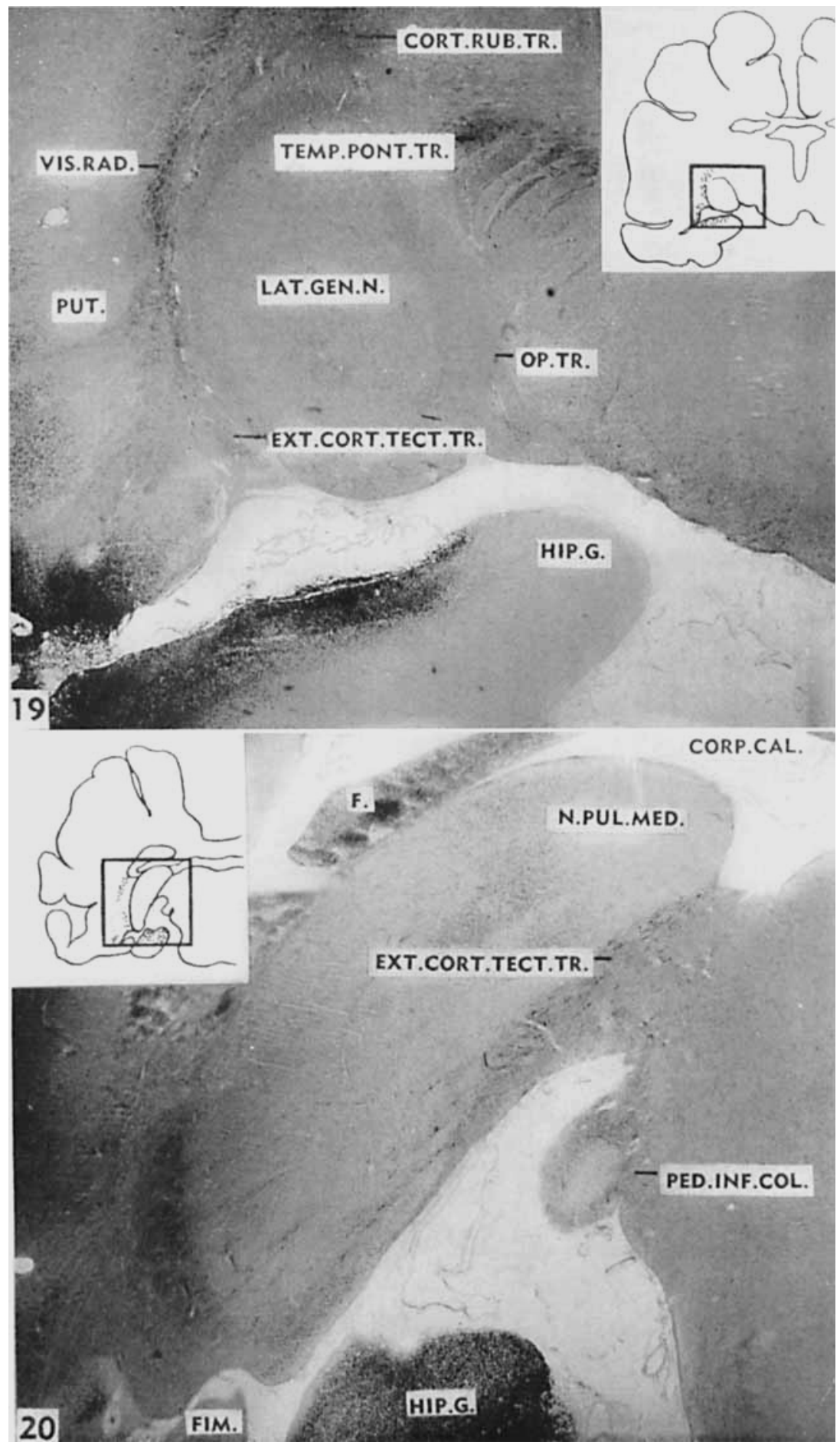

